\title{
EDITORIAL \\ Rear Admiral (Astronaut) Alan Shepard: De mortuis nil nisi bonum (say nothing bad of the departed)
}

\author{
John Rutka, MD, FRCSC \\ Department of Otolaryngology-Head and Neck Surgery, University of Toronto, Ontario, Canada
}

$\mathrm{T}$ He article by Menger et al. "Rear Admiral (Astronaut) Alan Shepard: Ménière's disease and the race to the moon" is a nice and engaging story to read. ${ }^{6}$ The protagonists of this drama as it unfolds were Alan Shepard (one of the original Mercury Seven astronauts) and Dr. William House (arguably the father of modernday neurotological surgery). Shepard's Ménière's disease threatened to abort his attempts toward further space travel, and in return he sought an experimental surgical procedure pioneered by Dr. House that thankfully was successful. The rest, as they say, is history. One can only imagine what screenwriters might do with a plot looking at all the other aspects of both lives (i.e., as a Christian Scientist, Shepard would have had to wrestle with his faith to have proceeded toward any form of surgery over prayer).

Fast forward a half century later, and although much is known about Ménière's disease it continues to confound all those who treat this condition. As a practicing neurotologist for more than 30 years I have studied histopathological specimens, done clinical research trials, been involved in meta-analyses and systematic reviewsyet I feel no further ahead in knowing what causes Ménière's. ${ }^{1,3-5,7-12,14-16}$ Much of that terra incognita feeling revolves around whether the pathophysiological process of endolymphatic hydrops is the actual cause leading to membrane ruptures within the inner ear (resulting in the admixing of perilymph and endolymph and the temporary loss of the endocochlear potential-the so-called $\mathrm{Na}^{+}-\mathrm{K}^{+}$ intoxication theory) or whether we are looking at an endstage pathological reaction attributable to a number of different pathologies. The frequency of bilateral involvement (up to $50 \%$ in some series) certainly speaks for consideration of a systemic cause (possibly immune mediated) being involved at some point in the disease process. The overriding clinical feature of anyone with Ménière's, however, is the presence of a condition associated with periods of remission and exacerbation. This feature undeniably makes it difficult to know whether any treatment (be- yond that of a total osseous labyrinthectomy) completely provides a $100 \%$ durable cure (please bear in mind that the price of doing a labyrinthectomy may be worse than the cause in some instances). Those who argue otherwise might best look at the myriad of publications still searching for the Holy Grail of treatment that returns inner ear function to normal and prevents further attacks of episodic vertigo/loss of hearing/tinnitus from occurring.

Without the ad fontes knowledge of all the facts surrounding Shepard's presentation, it must however have been extremely gratifying for both individuals to have had such a successful outcome for a condition whose pathogenesis remains elusive and capricious. Surgical assaults on the endolymphatic sac and its variation on a theme (including bony decompression, endolymphatic sac-mastoid shunting, sac resection, formal sac obliteration, sac revascularization and, in the case of Alan Shepard, an endolymphatic sac-subarachnoid shunt) have all had their proponents in the past. Much of our conventional belief in these procedures seems to have been questioned, however, in what later became known as "the Danish Sham Study" by Thomsen et al. In this double-blind, prospective, randomized controlled surgical trial, sac decompression surgery (the active arm) was compared to a placebo surgical arm. When unblinded, the researchers found no significant difference ultimately between the two procedures in terms of efficacy. As expected, their findings created a maelstrom of reinterpretations, alternative explanations, and different statistical analyses (not to mention the Helsinki Declaration on Medical Ethics weighing into the fray) of the data. In the end, however, one could not escape the finding that the placebo arm had had significant improvement (and seemingly better long-term results at a 9-year follow-up when compared to the active arm). ${ }^{2,13}$ The reluctance to perform sac surgery in many Northern European countries and my native Canada remains based in part on these findings and our own collective experience.

At the time, William House's surgical treatment of 
Alan Shepard was novel and not without controversy. If House's surgery had not been successful then one strongly doubts that Shepard would have been allowed to go on the Apollo 14 mission and to have a chance to walk on the moon. Had a negative result been made public it would have certainly damaged House's reputation. Upon reflection and with the passage of time, I have come to appreciate William House more as the equivalent of a modernday Thomas Alva Edison. He had an enquiring mind, was not afraid to look at things in different ways, and had that dogged determination to carry on with what he thought was right. His numerous accomplishments (of which there were many more) have been mentioned in this article. ${ }^{1}$ Perhaps more importantly, he literally had The Right Stuff (a purposeful double entendre acknowledging the title of the book by the late Tom Wolfe and a relevant read) and was able to convince generations of lateral skull base surgeons who followed in his footsteps that combined neurosurgi$\mathrm{cal} /$ neurotological team approaches specifically involving translabyrinthine and middle cranial fossa surgery had a vital role in the management of patients with vestibular schwannomas and other cerebellopontine angle lesions. To do so, House had to withstand not only the criticisms of the neurosurgical establishment of his day but also a few serious medicolegal challenges without faltering.

In the story of Alan Shepard and William House we ultimately see the right patient who had the right surgeon at their time of need. Evidence-based medicine tells a different story when one looks at Ménière's disease, but the story of Shepard and House in the Journal of Neurosurgery remains of interest not only in the space race but also in the history of medicine. Despite the apparently successful treatment for his Ménière's disease, I have my doubts that even now in the year 2019 Alan Shepard would have been allowed to continue in the space program, and he most certainly would not be allowed by federal law to operate a commercial or private plane without a co-pilot.

https://thejns.org/doi/abs/10.3171/2018.11.JNS182794

\section{References}

1. Bance M, Mai M, Tomlinson D, Rutka J: The changing direction of nystagmus in acute Meniere's disease: pathophysiological implications. Laryngoscope 101:197-201, 1991

2. Bretlau P, Thomsen J, Tos M, Johnsen NJ: Placebo effect in Meniere's disease: nine-year follow-up. Am J Otol 10:259261, 1989

3. Cohen-Kerem R, Kisilevsky V, Einarson TR, Kozer E, Koren G, Rutka JA: Intratympanic gentamicin in Meniere's disease: a meta-analysis. Laryngoscope 114:2085-2091, 2004

4. Kaplan DM, Hehar SS, Bance ML, Rutka JA: Intentional ablation of vestibular function using commercially available topical gentamicin-betamethasone eardrops in patients with Meniere's disease: further evidence for topical eardrop ototoxicity. Laryngoscope 112:689-695, 2002

5. Leong AC, Pothier DD, Rutka JA: Oral mycostatin as a possible alternative treatment for intractable Meniere's disease: preliminary cohort study. J Laryngol Otol 128:379-380, 2004

6. Menger R, Kelly P, Fernando S, Wolf ME, Martino A: Rear Admiral (Astronaut) Alan Shepard: Ménière's disease and the race to the moon. $\mathbf{J}$ Neurosurg [epub ahead of print February 15, 2019. DOI: 10.3171/2018.9.JNS182522]

7. Ruckenstein MJ, Rutka JA, Hawke M: The treatment of
Meniere's disease: Torok revisited. Laryngoscope 101:211218, 1991

8. Rutka JA, Barber HO: Recurrent vestibulopathy: third review. J Otolaryngol 15:105-107, 1986

9. Rutka JA, Nedzelski JM, Barber HO: Results of endolymphatic sac surgery for Meniere's disease. J Otolaryngol 13:70-72, 1984

10. Syed MI, Ilan O, Leong AC, Pothier DD, Rutka JA: Meniere's syndrome or disease: time trends in management and quality of evidence over the last two decades. Otol Neurotol 36:1309-1316, 2015

11. Syed MI, Ilan O, Nassar J, Rutka JA: Intratympanic therapy in Meniere's syndrome or disease: up to date evidence for clinical practice. Clin Otolaryngol 40:682-690, 2015

12. Syed MI, Rutka JA: In reference to systematic review and meta-analysis of Meniett therapy for Meniere's disease. Laryngoscope 125:E390, 2015

13. Thomsen J, Bretlau P, Tos M, Johnsen NJ: Meniere's disease: endolymphatic sac decompression compared with sham (placebo) decompression. Ann N Y Acad Sci 374:820-830, 1981

14. Thorp MA, Shehab ZP, Bance ML, Rutka JA: The AAOHNS Committee on Hearing and Equilibrium guidelines for the diagnosis and evaluation of therapy in Meniere's disease: have they been applied to published literature of the last decade? Clin Otolaryngol 28:173-176, 2003

15. Thorp MA, Shehab ZP, Bance ML, Rutka JA: Does evidence-based medicine exist in the treatment of Meniere's disease. A critical review of the last decade of publications. Clin Otolaryngol 25:456-461, 2000

16. Yazdi AK, Rutka J: Results of labyrinthectomy in the treatment of Meniere's disease and delayed endolymphatic hydrops. J Otolaryngol 25:26-31, 1996

\section{Disclosures}

The author reports no conflict of interest.

\section{Correspondence}

John Rutka: john.rutka@uhn.on.ca.

\section{INCLUDE WHEN CITING}

Published online February 15, 2019; DOI: 10.3171/2018.11.JNS182794.

\section{Response}

\section{Patrick D. Kelly, MD}

Department of Neurosurgery, Vanderbilt University Medical Center, Nashville, Tennessee

We thank Dr. Rutka for his thoughtful editorial on our article. His valuable perspective sets the context in which this episode of Alan Shepard and William House unfolded.

The pathophysiology of Ménière's remains elusive despite years of research, including Dr. Rutka's own substantial contributions. Evidence for the first surgical procedures for Ménière's disease was fraught with design limitations, and chief among these is the "regression to the mean" phenomenon. Treating only the most refractory cases of a relapsing condition at their zenith will, by definition, give misleading results. ${ }^{1}$

The antidote for regression to the mean, of course, is randomization. ${ }^{3}$ As Dr. Rutka explains, the 1981 randomized trial of simple mastoidectomy (control) versus Silastic sheet mastoid shunt (active treatment) suggested equal efficacy of the two procedures in treating Ménière's. ${ }^{5}$ Nota- 
bly, however, there was a roughly $70 \%$ success rate in each group, indicating either a sizable placebo or regression-tothe-mean effect, or that some aspect of a mastoidectomy had an unanticipated therapeutic benefit. ${ }^{4}$ It seems that there was just enough opportunity to critique this study to permit the debate to continue.

We agree wholeheartedly with Dr. Rutka's characterization of House as a modern-day Thomas Edison. He was certainly a pioneer in many ways, and-like most innovators-faced a considerable amount of resistance from his peers in that era. ${ }^{2}$ The endolymphatic-subarachnoid shunt, though, may simply have been one of House's own "ways not to make a lightbulb."

As Dr. Rutka suggests, this episode would have significant scrutiny in today's military pilot and space exploration communities. Alan Shepard's tale is in equal parts a testament to his fateful encounter with Dr. House, to his own aeronautic abilities, and perhaps to the fortunate circumstances that only personal relationships can forge. We hope that this vignette offers a window into the important role not just of an American space explorer but of a major figure in skull base surgery. Their "right stuff" changed the course of history.

\section{References}

1. Bland JM, Altman DG: Statistics notes: some examples of regression towards the mean. BMJ 309:780, 1994

2. Eisenberg LS: The contributions of William F. House to the field of implantable auditory devices. Hearing Res 322:5256,2015

3. Jonas WB, Crawford C, Colloca L, Kaptchuk TJ, Moseley B, Miller FG, et al: To what extent are surgery and invasive procedures effective beyond a placebo response? A systematic review with meta-analysis of randomised, sham controlled trials. BMJ Open 5:e009655, 2015

4. Sajjadi H, Paparella MM: Meniere's disease. Lancet 372:406-414, 2008

5. Thomsen J, Bretlau P, Tos M, Johnsen NJ: Meniere's disease: endolymphatic sac decompression compared with sham (placebo) decompression. Ann N Y Acad Sci 374:820-830, 1981

\section{INCLUDE WHEN CITING}

Published online February 15, 2018; DOI: 10.3171/2018.11.JNS183232.

\section{Correspondence}

Patrick D. Kelly: patrick.d.kelly@vumc.org. 